\title{
Infliximab-induced remission improves physical activity in patients with active Crohn's disease
}

\author{
D Fernando de Azevedo Lucca ${ }^{\mathbf{1}}$ \\ (iD) Carla Malaguti \\ (iD) Liliana Andrade Cheb/i \\ (iD) Maycon Moura Reboredo, \\ (i) Bruno Valle Pinheiro ${ }^{2}$ \\ Tarsila Campanha da Rocha Ribeiro' \\ (iD) Felipe Meirelles de Azevedo ${ }^{3}$ \\ (iD) José Otávio do Amaral Corrêa \\ (i) Pedro Duarte Gaburri \\ (D) Julio Maria Fonseca Chebli
}

\begin{abstract}
1. Unidade de Gastroenterologia, Departamento de Medicina, Centro de Doenças Inflamatórias Intestinais, Hospital Universitário da Universidade Federal de Juiz de Fora, Faculdade de Medicina da Universidade Federal de Juiz de Fora, Juiz de Fora, MG, Brasi

2. Laboratório de Investigação Pulmonar, Universidade Federal de Juiz de Fora, Juiz de Fora, MG, Brasil. 3. Programa de Pós-Graduação em Ciências da Reabilitação e Desempenho Físico-Funcional da Universidade Federal de Juiz de Fora, Faculdade de Medicina da Universidade Federal de Juiz de Fora, Juiz de Fora, MG, Brasil.
\end{abstract}

http://dx.doi.org/10.1590/1806-9282.66.11.1566

\section{SUMMARY}

AIM: To compare the level of physical activity (PA), exercise capacity, and body composition before and after infliximab-induced clinical remission in patients with Crohn's disease (CD).

METHODS: This prospective longitudinal study evaluated 44 adult outpatients with active CD before infliximab administration and 24 weeks after infliximab therapy. The patients were evaluated for PA in daily life, exercise capacity, muscle strength, and body composition.

RESULTS: 38 (86.4\%) patients achieved infliximab-induced remission at 24 weeks and presented an increment in the number of steps taken of 1092 ( $7440 \pm 2980$ vs. $6348 \pm 3177$, respectively; $p=0.006$ ). The inactive time was reduced when compared to the baseline value (454.2 \pm 106.3 vs. $427.9 \pm 97.8$, respectively; $p=0.033$ ). There was no difference in the distance walked before and after infliximab therapy, while there was an increase in the fat mass index in responders to infliximab compared to the baseline (19.1 $\pm 7.6 \mathrm{vs}$. 14.9 \pm 5.8 ; $p=0.001)$.

CONCLUSIONS: Infliximab-induced remission was shown to be effective for increasing physical activity by improving the number of steps and reducing inactive time. The maintenance of clinical remission associated with incentives to regular PA may contribute to making these patients reach an ideal level of PA.

KEYWORDS: Crohn disease. Inflammatory Bowel Diseases. Infliximab. Motor activity.

\section{INTRODUCTION}

Crohn's disease (CD) is a chronic, transmural, and idiopathic inflammatory bowel disease (IBD) that can involve any segment of the gastrointestinal tract. The incidence of IBD and CD has been rising with an annual incidence ranging from 3 to 20 cases per
100,000. Its relapsing-remitting course can negatively impact patient social, educational, and professional activities, hence having a profound effect on their health-related quality of life (HRQOL) 1 .

During the last decades, the impact of physical

DATE OF SUBMISSION: 07-May-2020

DATE OF ACCEPTANCE: 11-Jul-2020

CORRESPONDING AUTHOR: Julio Maria Fonseca Chebli

Rua Maria José Leal, 296- Juiz de Fora, MG, Brasil - CEP 36036-247 Tel / Fax: +55 (32) 21023841.

E-mail: chebli@globo.com 
activity (PA) on health has been recognized in several areas. Its role in healthy subjects is associated with an improvement of physical, psychosocial/social, and cognitive fields as well as an enhancement in $\mathrm{HRQOL}^{2}$. Moreover, PA has also been proven to increase HRQOL and reduce all-cause mortality even in patients with chronic diseases such as type 2-diabetes, arthritis, and cancer $^{3}$. Thus, PA is considered a predictor of public health, and the definition of an individual as physically inactive has a critical impact further on patient management ${ }^{4}$.

Although the role of PA in IBD patients is not well defined, some studies about its effect on the disease's etiology and activity have addressed this issue ${ }^{5,6}$. IBD patients, mainly those with $\mathrm{CD}$, seem to have a lower level of PA when compared to controls ${ }^{7}$. Tew et al. ${ }^{8}$ evaluated 877 IBD patients and demonstrated that the majority of them were minimally active or inactive, and this sort of behavior was associated with disease activity. The lower PA level in this population can be explained by a multifactorial scenario. Disease manifestations (e.g., diarrhea, abdominal pain, sarcopenia, osteoporosis, and fatigue) associated with mood disorders may contribute to the sedentary lifestyle of these patients, resulting in the reduction of their physical performance ${ }^{9}$. Of note, the impact of PA on the immune function has been demonstrated in nonIBD populations, and it is hypothesized that it could be related to its anti-inflammatory effect by decreasing visceral fat tissue and releasing pro-inflammatory cytokines/myokines ${ }^{10}$.

Biological therapy represented a significant advance for CD treatment, reducing hospitalizations, surgical interventions, and achieving good rates of clinical remission of the disease $\mathrm{e}^{11}$. Taking into account that a low level of PA may be associated with disease activity $^{12}$, it seems very interesting to investigate it after infliximab (IFX)-induced remission. This study evaluated a cohort of patients with active CD submitted to IFX therapy in order to compare the exercise capacity and PA before and after IFX-induced clinical remission. It is hypothesized that $\mathrm{CD}$ patients who achieved IFX-induced remission present a significant improvement in the previous levels of exercise capacity and PA in daily life.

\section{METHODS}

This prospective longitudinal study, with a beforeand after-intervention, was conducted between March
2014 and June 2017, on adult outpatients with CD from the Inflammatory Bowel Disease Center at the University Hospital of the Federal University of Juiz de Fora, Brasil. The study was approved by the institutional Ethical Committee (number 95,125). All patients provided informed consent.

We included patients with $C D$, aged $\geq 18$ years and under 65 years, with a 3-month history of active disease, defined as a Harvey-Bradshaw index (HBI) score $\geq 5$, with an indication for anti-TNF (anti-tumor necrosis factor- $\alpha$ ) therapy.

Exclusion criteria were: severe disease requiring hospitalization or immediate surgery, history of recent surgery, previous treatment with an anti-TNF agent or other biologic therapy, short-bowel syndrome, ostomy, class II or III obesity, severe hepatic disease, immunodeficiency syndromes, end-stage renal disease, neuromuscular diseases, malignancy, hemoglobin level below $11 \mathrm{~g} / \mathrm{dL}$ at baseline, participation in a formal exercise training program in the preceding 6 months.

Eligible patients received induction therapy consisting of intravenous injections of $5 \mathrm{mg} / \mathrm{Kg}$ of IFX at weeks 0,2 , and 6 , followed by maintenance infusion $(5 \mathrm{mg} / \mathrm{Kg})$ at weeks 14 and 22 . Participants were followed-up until week 24. Doses of concomitant medications were maintained constant except for those using steroids, for which the dose could be reduced.

Each one of the patients was evaluated at two different moments: M1, before IFX administration (baseline) and M2, 24 weeks after IFX therapy. The primary endpoint was an increase in the total number of steps/ day in daily life. HBI, anthropometry and body composition, physical activity in daily life, exercise capacity, peripheral muscle strength, and Hospital Anxiety and Depression Scale (HADS) were assessed in all patients.

At entry, the eligibility criteria were assessed and medical history was recorded, including age, gender, smoking status, and body mass index. The disease-associated variables recorded were duration of disease, location and phenotype of $\mathrm{CD}$ according to the Montreal classification ${ }^{13}$, CD activity, current therapy, and CD-related surgical history. CD behavior was established by both ileocolonoscopy and computed enterography performed within six months prior to study entry. An HBI score $\geq 5$ indicated active disease, while clinical remission after infliximab therapy was defined by a HBI less than $5^{14}$. For practical purposes, patients were categorized as non-responders to the IFX therapy if a failure to achieve clinical remission (i.e., $\mathrm{HBI} \leq 4$ ) from baseline was registered following 
anti-TNF therapy, as assessed at 24 weeks after the initial infusions.

Physical activity in daily life was monitored by DynaPort Activity Monitor (McRoberts BV, Netherlands) used at least four days in order to obtain the total number of steps/day, active time, and inactive time $^{15}$. Anthropometry and body composition measurements for the assessment of lean mass and fat mass were obtained by electrical bioimpedance (Quantum BIA-101Q, Detroit, MI) ${ }^{16}$. Exercise capacity was evaluated by the Shuttle Walk Test (SWT) ${ }^{17}$, in which the total distance covered in meters indicates the exercise capacity. The handgrip strength (HS) was assessed by a hydraulic dynamometer (SAEHAN ${ }^{\circledR}$, Korea) in $\mathrm{Kg} / \mathrm{f}^{18}$. Anxiety and depression levels were assessed using the HADS, validated for the Brazilian population. According to the validated translations of the HADS, the cutoff value for depressive or anxiety symptoms was $8^{19}$.

\section{Statistical analysis}

Statistical analysis was performed using SPSS20.0 (SPSS, Chicago, USA). The Wilcoxon test was used to non-parametric variables, which were described in medians and interquartile intervals. The paired t-test was used for evaluating parametric variables.

To detect this $20 \%$ difference in the number of steps taken by CD patients before and after Infliximab-induced remission, with $90 \%$ power and a $5 \%$ significance level using a one-sided test, the required sample size is at least 40 patients, considering an IFX-induced remission rate at 24 weeks of $70 \%$. The number of patients was increased to 44 to compensate for an anticipated dropout rate of $10 \%$.

Comparisons before and after infliximab-induced remissions on the same subjects were performed for PA, exercise capacity, peripheral muscle strength, LM and FM indices. This same analysis was carried out for patients categorized as primary non-responders to anti-TNF therapy. Statistical significance was set $\mathrm{p}<0.05$.

\section{RESULTS}

A total of 50 adult CD patients were assessed for eligibility in the study. Among them, 3 (5.8\%) patients were excluded because they presented indeterminate colitis, class III obesity, or contraindications to antiTNF therapy. In addition, 3 (5.8\%) subjects discontinued the study, 2 due to an adverse event, and 1 for missing the follow-up. Consequently, 44 patients completed 24 weeks of the complete evaluation. The baseline characteristics of the participants are shown in Table 1 . The mean $( \pm \mathrm{SD})$ patient age was $39.9( \pm 12.5)$, and $56.8 \%$ were females. The mean duration of the disease was 6.5 years. The most common location and phenotype of CD were Ileocolonic (61.4\%) and stricturing (56.8\%), respectively. Prior resections were performed in $31.8 \%$ of patients. At the baseline, $20.5 \%$ were under steroids and $86.4 \%$ thiopurines therapy. Of the total population, 38 (86.4\%) patients achieved IFX-induced clinical remission at the end of the 24 weeks, while $6(13.6 \%)$ were non-responders to anti-TNF.

Patients who responded to the IFX treatment did not differ on the baseline and during clinical remission at week 24 in terms of peripheral muscle strength and LM index. In contrast, there was a higher increase in the FM index in responders following IFX therapy compared to the baseline period (19.1 $\pm 7.6 \mathrm{vs} .14 .9 \pm 5.8$; $\mathrm{p}=0.001$; Table 2). Participants with CD refractory to anti-TNF therapy did not present any significant change in body composition or skeletal muscle function after receiving IFX (Table 3).

TABLE 1. BASELINE DEMOGRAPHIC AND CLINICAL CHARACTERISTICS OF PATIENTS WITH CROHN'S DISEASE RECEIVING INFLIXIMAB (N=44)

\begin{tabular}{|c|c|}
\hline \multicolumn{2}{|l|}{ Characteristic } \\
\hline Gender, (M:F) & $19: 25$ \\
\hline Age, $(y r)^{*}$ & $39.9 \pm 12.5$ \\
\hline \multicolumn{2}{|l|}{ Race, n (\%) } \\
\hline White & $36(81.8)$ \\
\hline Non-white & $8(18.2)$ \\
\hline Body-mass index, $\left(\mathrm{kg} / \mathrm{m}^{2}\right)^{\star}$ & $22.4 \pm 3.3$ \\
\hline Current smoker, n (\%) & $12(27.3)$ \\
\hline \multicolumn{2}{|l|}{ Disease location, n (\%) } \\
\hline$[\mathrm{L} 1 / \mathrm{L} 2 / \mathrm{L} 3]$ & $10(22.7) / 7(15.9) / 27(61.4)$ \\
\hline \multicolumn{2}{|l|}{ Disease behavior, n (\%) } \\
\hline [B1/B2/B3] & $11(25) / 25(56.8) / 8(18.2)$ \\
\hline p (perianal disease) & $10(22.7)$ \\
\hline Disease duration, $(y r)^{\star}$ & $6.5 \pm 5.8$ \\
\hline HBI score ${ }^{\star}$ & $6.0(2-18)$ \\
\hline $\begin{array}{l}\text { Previous intestinal resections, } \\
\mathrm{n}(\%)\end{array}$ & $14(31.8)$ \\
\hline \multicolumn{2}{|l|}{$\begin{array}{l}\text { Concurrent therapy at study } \\
\text { entry, n (\%) }\end{array}$} \\
\hline Glucocorticoids & $9(20.5)$ \\
\hline Thiopurines & $38(86.4)$ \\
\hline Glucocorticoids plus thiopurines & $2(4.5)$ \\
\hline
\end{tabular}


TABLE 2. EXERCISE CAPACITY, PHYSICAL ACTIVITY IN DAILY LIFE, AND BODY COMPOSITION IN CROHN'S DISEASE PATIENTS BEFORE AND AFTER INFLIXIMAB-

INDUCED CLINICAL REMISSION ( $\mathrm{N}=38)$

\begin{tabular}{l|l|l|l} 
Variable $^{*}$ & $\begin{array}{l}\text { Before IFX } \\
\text { therapy } \\
\text { (Active CD) }\end{array}$ & $\begin{array}{l}\text { After IFX } \\
\text { therapy } \\
(\text { Inactive CD) }\end{array}$ & $P$ \\
\hline HADS-D 5 & $5.62 \pm 3.63$ & $3.81 \pm 2.63$ & 0.007 \\
\hline HADS-A & $7.48 \pm 4.20$ & $4.97 \pm 3.57$ & 0.001 \\
\hline HBI score & $6.0(1-18)$ & $1.58(0-4)$ & $<0.001$ \\
\hline Shuttle walking test (m) & $532.2 \pm 222.3$ & $586.5 \pm 252.4$ & 0.10 \\
\hline Body composition $(\mathrm{Kg})$ & & & \\
\hline Lean mass index & $46.7 \pm 8.5$ & $48.3 \pm 10.8$ & 0.11 \\
\hline Fat mass index & $14.9 \pm 5.8$ & $19.1 \pm 7.6$ & 0.001 \\
\hline $\begin{array}{l}\text { Isometric handgrip force } \\
\text { (kgf) }\end{array}$ & $33.8 \pm 10.7$ & $34 \pm 10.8$ & 0.92 \\
\hline $\begin{array}{l}\text { Physical activities in } \\
\text { daily life }\end{array}$ & & & 0.09 \\
\hline Active time (min) & $237.8 \pm 93.4$ & $255.6 \pm 90.6$ & 0.033 \\
\hline \begin{tabular}{l} 
Inactive time (min) \\
\hline Steps/day
\end{tabular} & $454.2 \pm 106.3$ & $427.9 \pm 97.8$ & 0.006 \\
\hline
\end{tabular}

*Values are expressed as mean and standard deviation. Abbreviations: $C D=C$ rohn's disease; $\mid F X=$ infliximab; $\mathrm{HBI}=$ Harvey-Bradshaw Index.

TABLE 3. EXERCISE CAPACITY, PHYSICAL ACTIVITY IN DAILY LIFE, AND BODY COMPOSITION IN CROHN'S DISEASE PATIENTS NON-RESPONDERS TO INFLIXIMAB THERAPY $(\mathrm{N}=6)$

\begin{tabular}{l|l|l|l} 
Variable* & $\begin{array}{l}\text { Before IFX } \\
\text { therapy } \\
\text { (Active CD) }\end{array}$ & $\begin{array}{l}\text { After IFX } \\
\text { therapy } \\
\text { (Inactive CD) }\end{array}$ & $P$ \\
\hline $\mathrm{HBI}$ score & $8.50(6-16)$ & $8.0(1-13)$ & 0.85 \\
\hline Shuttle walking test $(\mathrm{m})$ & $693.3 \pm 369.5$ & $728.3 \pm 294.3$ & 0.75 \\
\hline Body composition $(\mathrm{Kg})$ & & & \\
\hline Lean mass index & $48.1 \pm 7.7$ & $48.5 \pm 5.5$ & 0.82 \\
\hline Fat mass index & $15.1 \pm 5.6$ & $18.1 \pm 8.6$ & 0.13 \\
\hline $\begin{array}{l}\text { Isometric handgrip force } \\
\text { (kgf) }\end{array}$ & $32.8 \pm 12.2$ & $36.4 \pm 9.8$ & 0.27 \\
\hline $\begin{array}{l}\text { Physical activities in daily } \\
\text { life }\end{array}$ & & & 0.30 \\
\hline Active time (min) & $178.2 \pm 84.4$ & $200.5 \pm 77.2$ & 0.34 \\
\hline $\begin{array}{l}\text { Inactive time (min) } \\
\text { Steps/day }\end{array}$ & $517.6 \pm 106.3$ & $484.1 \pm 106.1$ & 0.86 \\
\hline
\end{tabular}

*Values are expressed as mean and standard deviation. Abbreviations: IFX= infliximab; $\mathrm{HBI}=$ Harvey-Bradshaw Index

There was no difference in the distance walked in the SWT performed before and after anti-TNF therapy. At week 24, patients who achieved IFX-induced remission presented a significant increment from baseline in the number of steps taken of 1092 (7440 $\pm 2980 v s .6348 \pm 3177$, respectively; $\mathrm{p}=0.006$ ). Of note, 18 out of 38 responder patients (47.3\%) reached the mark of 7500 steps. Additionally, inactive time was reduced over clinical remission at week 24 compared to the baseline period $(454.2 \pm 106.3 v s .427 .9 \pm 97.8$, respectively; $\mathrm{p}=0.033)$. Also, there was an increment in active time during the remission period compared to the baseline, although this difference did not reach significance (255.6 $\pm 90.6 \mathrm{vs} .237 .8 \pm 93.4$, respectively; $\mathrm{p}=0.09$ ). On the other hand, non-responders to IFX did not present any significant changes in the active time, inactive time, number of steps taken per day, and distance walked in the SWT (Table 3).

There was a decrease in anxiety and depression scores following IFX-induced remissions compared with the baseline status (Table 2). Nonetheless, the mean depression or anxiety scores throughout the study period remained below 8 , indicating that subjects presented psychological scores within a normal range.

\section{DISCUSSION}

The current study has demonstrated that CD patients that achieve IFX-induced remission present an improvement in PA levels in daily life. To the best of our knowledge, this is the first study that compared objectively measures of daily PA post infliximab intervention, in eligible patients with active $C D$, to this induction therapy.

It is well known that PA offers many benefits to health even for those who have chronic diseases ${ }^{4}$. The American College of Sports Medicine ${ }^{20}$ recommends at least 30 minutes of moderate aerobic activity for five days a week, or 20 minutes of heavy aerobic activity 3-times/week. Tudor-Locke et al. ${ }^{15}$ demonstrated that $30 \mathrm{~min} /$ day of moderate-to-vigorous PA translated into approximately 7500 steps/day. In our study, IFX responders presented a increase in the number of steps/day i.e., notably nearly $50 \%$ of patients reached the mark of 7500 steps. Interestingly, another investigation noticed that an increase in 1000 steps daily was of clinical relevance to people's health ${ }^{21}$. In this context, our research demonstrated that an average increase of 1092 steps occurred in those patients who reached clinical remission.

The PA levels improvement observed after IFX-induced remission in our investigation may define disease activity as responsible for the inability of active CD patients to exercise. In this sense, we observed that patients with IFX refractory-CD have not changed their outcome in terms of active time, inactive time, number of steps taken per day, and distance walked in the SWT. It has also been demonstrated that regular $\mathrm{PA}$ is uncommon in IBD patients and about $40 \%$, even though with the disease in remission, have particularly 
fatigue, joint or abdominal pain as the most common barriers to exercises. Although most of these symptoms disappear with disease remission, they yet avoid doing it for fear, shame, or insecurity because there are no restrooms nearby ${ }^{22}$. During the last decade, there has been an increase in the number of studies investigating PA in $\mathrm{IBD}^{9,12,23}$. However, most of such studies have focused on the evaluation of PA but none have investigated the influence of biological therapy on its behavior. Just one of them has employed an accelerometer in $\mathrm{CD}$ patients in remission or in active disease, and no difference was observed between both groups. Moreover, this was a transversal study including a small sample of patients ${ }^{24}$.

It is of clinical importance to highlight that the aim of our investigation was to reach a higher level of PA in active CD patients following IFX-induced clinical remission. It should be emphasized that Jones et al. demonstrated that among patients with CD in remission, those with higher exercise levels were significantly less likely to develop active disease at 6 months ${ }^{23}$. Furthermore, an inverse relationship was demonstrated between PA and chronic disease evolution, and higher levels of PA were associated with lower mortality risk, taking into account all causes of death ${ }^{4,20}$.

We also found an increase in the FM index, not accompanied by the LM index in those on clinical remission. Weight loss has been recognized as part of the clinical features of several patients with active $\mathrm{CD}$, although other researchers have described a FM increase after IFX therapy ${ }^{25}$. We believe that this FM increase after disease control may be a consequence of the improvement in quantitative as well as qualitative food intake after biological therapy due to the absence of abdominal symptoms as well as lower catabolism in consequence of better intestinal inflammation control.

Changes in functional capacity estimated by SWT and maximal strength have not been found in the group on clinical remission. Although active CD can lead to sarcopenia and a sedentary lifestyle, it is possible to speculate that the functional capacity of exercising may be preserved in our sample, particularly because it was composed mainly of young adults and with short disease duration. In consequence, the systemic effects that can occur in CD can be light with less impact on functional capacity in this group of patients.

Improvement in PA levels may represent one very important gain induced by biological therapy, besides the benefits previously reported related to symptom remission and mucosal healing. The maintenance of clinical remission associated with incentives to regular PA may contribute to making that these patients reach an ideal level of PA, according to recommendations, not only to improve life quality but also to reduce the risk of neoplasm and general levels of mortality 3,4,20,23.

This study presents some limitations: patients with CD were in a tertiary IBD referral center, which tends to make them more likely to have more severe CD than those seen in an outpatient medical care setting. The lack of healthy controls and non-random sample makes it impossible to determine the real impact of IFX treatment on PA levels. Therefore, the hypotheses raised here should be compared with data obtained from future longitudinal studies. Despite these limitations, our findings are useful to show behavior about daily PA habits in patients with CD during disease activity and remission. Furthermore, it should be emphasized that the prospective nature of the present study allowed the systematic and full collection of data, which is an important strength to be considered. Future prospective longitudinal studies are necessary, including a standardized physical activity protocol aimed at patients with remission CD to investigate whether gradually incremented PA results in improved outcomes.

\section{CONCLUSION}

IFX-induced clinical remission followed by maintenance therapy has shown to be effective for increasing PA levels in daily life as well as reduced inactive time on patients with active $\mathrm{CD}$. Given the important role of PA for patients with CD, anti-TNF therapy may be a useful therapeutic strategy along with targeted recommendations for increasing PA levels.

\section{Conflicts of Interest}

J.M.F. Chebli has served as a speaker for Abbott, Abbvie, Janssen, and Takeda. For the remaining authors, there is no conflict to be declared. The authors confirm that this article content presents no conflicts of interest.

\section{Disclosure of funding}

Partially supported by Fundação de Amparo à Pesquisa do Estado de Minas Gerais (FAPEMIG), Conselho Nacional de Desenvolvimento Científico e Tecnológico (CNPq) and by the Coordenação de Aperfeiçoamento de Pessoal de Nível Superior - Brasil (CAPES) - Finance Code 001. 


\section{Author's Contribution}

Luca FA: Data curation, investigation, project management, writing - original draft; Malaguti C: Conceptualization, investigation, methodology, supervision, writing - original draft; Chebli LA: Conceptualization, funding, resources, writing - original and final approval; Reboredo MM: Investigation, formal analysis, visualization, writing - original draft; Pinheiro BV: Conceptualization, methodology, funding, resources, writing - original and final approval; Ribeiro TCR:
Data curation, project management, formal analysis, resources; Azevedo FM: Data curation, investigation, formal analysis, interpretation of data; Corrêa JOA: Conceptualization, formal analysis, resources, software, writing - original draft; Gaburri PD: Conceptualization, methodology, visualization, writing - original draft; Chebli JMF: Conceptualization, funding acquisition, project management, resources, supervision, visualization, writing - review \& editing.

\section{RESUMO}

OBJETIVO: Comparar o nível de atividade física (AF), capacidade de exercício e composição corporal antes e após remissão clínica induzida por infliximabe em pacientes com doença de Crohn (DC).

MÉTODOS: Neste estudo longitudinal prospectivo, foram envolvidos 44 pacientes ambulatoriais adultos com DC ativa avaliados antes e depois de 24 semanas de terapia com infliximabe. Os pacientes foram avaliados quanto à AF, capacidade de exercício, força muscular e composição corporal.

RESULTADOS: 38(86,4\%) pacientes alcançaram remissão induzida por infliximabe em 24 semanas e apresentaram aumento no número de passos de 1092 ( $7440 \pm 2980$ vs. 6348 \pm 3177 , respectivamente; $p=0,006)$. O tempo de inatividade foi reduzido quando comparado ao

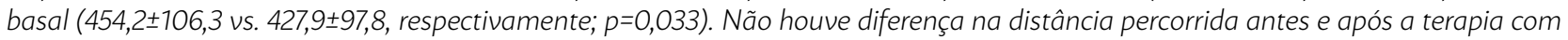

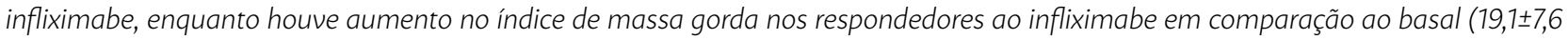
vs. $14,9 \pm 5,8 ; p=0,001$.

CONCLUSÕES: A remissão induzida pelo infliximabe mostrou-se eficaz no aumento da atividade física, melhorando o número de passos e reduzindo o tempo inativo. A manutenção da remissão clínica associada a incentivos à AF regular pode contribuir para que esses pacientes atinjam um nivel ideal de AF.

PALAVRAS-CHAVE: doença de Crohn, doença inflamatória intestinal, infliximabe, atividade física

\section{REFERENCES}

1. Molodecky NA, Soon IS, Rabi DM, Ghali WA, Ferris M, Chernoff G, et al. Increasing incidence and prevalence of the inflammatory bowel diseases with time, based on systematic review. Gastroenterology. 2012;142(1):46-54.

2. Anokye NK, Trueman P, Green C, Pavey TG, Taylor RS. Physical activity and health related quality of life. BMC Public Health. 2012;12:624.

3. Kruk J, Czerniak U. Physical activity and its relation to cancer risk: updating the evidence. Asian Pac J Cancer Prev. 2013;14(7):3993-4003.

4. Fishman El, Steeves |A, Zipunnikov V, Koster A, Berrigan D, Harris TA, et al. Association between objectively measured physical activity and mortality in NHANES. Med Sci Sports Exerc. 2016;48(7):1303-11.

5. D'Incà R, Varnier M, Mestriner C, Martines D, D'Odorico A, Sturniolo GC. Effect of moderate exercise on Crohn's disease patients in remission. Ital j Gastroenterol Hepatol. 1999;31(3):205-10.

6. Bilski ,, Mazur-Bialy A, Brzozowski B, Magierowski M, Zahradnik-Bilska ], Wójcik D, et al. Can exercise affect the course of inflammatory bowel disease? Experimental and clinical evidence. Pharmacol Rep. 2016;68(4):827-36.

7. Mack DE, Wilson PM, Gilmore JC, Gunnell KE. Leisure-time physical activity in Canadians living with Crohn disease and ulcerative colitis: population-based estimates. Gastroenterol Nurs. 2011;34(4):288-94.

8. Tew GA, Jones K, Mikocka-Walus A. Physical activity habits, limitations, and predictors in people with inflammatory bowel disease: a large cross-sectional online survey. Inflamm Bowel Dis. 2016;22(12):2933-42.

9. Shephard RJ. The case for increased physical activity in chronic inflammatory bowel disease: a brief review. Int J Sports Med. 2016;37(7):505-15.
10. Brolinson PG, Elliott D. Exercise and the immune system. Clin Sports Med. 2007;26(3):311-9.

11. Hanauer SB, Feagan BG, Lichtenstein GR, Mayer LF, Schreiber S, Colombel JF, et al. Maintenance infliximab for Crohn's disease: the ACCENTI randomised trial. Lancet. 2002;359(9317):1541-9.

12. Engels M, Cross RK, Long MD. Exercise in patients with inflammatory bowel diseases: current perspectives. Clin Exp Gastroenterol. 2017;11:1-11.

13. Silverberg MS, Satsangi J, Ahmad T, Arnott ID, Bernstein CN, Brant SR, et al. Toward an integrated clinical, molecular and serological classification of inflammatory bowel disease: report of a Working Party of the 2005 Montreal World Congress of Gastroenterology. Can | Gastroenterol. 2005;19(Suppl A):5A-36A.

14. Elliott PR, Lennard-Jones JE, Hathway N. Simple index of Crohn's disease activity. Lancet. 1980;1(8173):876.

15. Tudor-Locke C, Leonardi C, Johnson WD, Katzmarzyk PT, Church TS. Accelerometer steps/day translation of moderate-to-vigorous activity. Prev Med. 2011;53(1-2):31-3.

16. Barbosa-Silva MC, Barros AJ, Wang J, Heymsfield SB, Pierson RN Jr. Bioelectrical impedance analysis: population reference values for phase angle by age and sex. Am J Clin Nutr. 2005;82(1):49-52.

17. Singh SJ, Morgan MD, Scott S, Walters D, Hardman AE. Development of a shuttle walking test of disability in patients with chronic airways obstruction. Thorax. 1992;47(12):1019-24.

18. Angst F, Drerup S, Werle S, Herren DB, Simmen BR, Goldhahn J. Prediction 
of grip and key pinch strength in 978 healthy subjects. BMC Musculoskelet Disord. 2010;11:94.

19. Botega NJ, Bio MR, Zomignani MA, Garcia C Jr, Pereira WA. Mood disorders among inpatients in ambulatory and validation of the anxiety and depression scale HAD. Rev Saude Publica. 1995;29(5):355-63.

20. Garber CE, Blissmer B, Deschenes MR, Franklin BA, Lamonte MI, Lee IM, et al; American College of Sports Medicine. American College of Sports Medicine position stand. Quantity and quality of exercise for developing and maintaining cardiorespiratory, musculoskeletal, and neuromotor fitness in apparently healthy adults: guidance for prescribing exercise. Med Sci Sports Exerc. 2011;43(7):1334-59.

21. Dwyer T, Ponsonby AL, Ukoumunne OC, Pezic A, Venn A, Dunstan $D$, et al. Association of change in daily step count over five years with insulin sensitivity and adiposity: population based cohort study. BMJ. 2011;342:c7249

22. Chae J, Yang HI, Kim B, Park SI, Jeon JY. Inflammatory bowel disease patients' participation, attitude and preferences toward exercise. Int J Sports Med. 2016;37(8):665-70.

23. Jones PD, Kappelman MD, Martin CF, Chen W, Sandler RS, Long MD. Exercise decreases risk of future active disease in patients with inflammatory bowel disease in remission. Inflamm Bowel Dis. 2015;21(5):1063-71.

24. van Langenberg DR, Papandony MC, Gibson PR. Sleep and physical activity measured by accelerometry in Crohn's disease. Aliment Pharmacol Ther. 2015;41(10):991-1004.

25. Vadan R, Gheorghe LS, Constantinescu A, Gheorghe C. The prevalence of malnutrition and the evolution of nutritional status in patients with moderate to severe forms of Crohn's disease treated with Infliximab. Clin Nutr. 2011;30(1):86-91. 